\title{
Noninvasive ventilation prescription and association with outcome in elders admitted for acute heart failure in Emergency Departments - A retrospective analysis.
}

La prescription de la Ventilation non-invasive aux urgences et association avec le pronostic des patients âgés admis aux urgences pour insuffisance cardiaque - Une analyse rétrospective

Marina GILLET, MD

Emergency Department and Prehospital Care, University Hospital of Poitiers marina.gillet@chu-poitiers.fr

Jérémy GUENEZAN, MD

Emergency Department and Prehospital Care, University Hospital of Poitiers University of Poitiers, School of Medicine

jeremy.guenezan@chu-poitiers.fr

Matthieu MARCHETTI, MD

Emergency Department and Prehospital Care, University Hospital of Poitiers matthieu.marchetti@chu-poitiers.fr

Erwan L'HER, MD PhD

Intensive Medical Care Unit, University Hospital of Brest

erwan.1her@chu-brest.fr

Olivier MIMOZ, MD PhD

Emergency Department and Prehospital Care, University Hospital of Poitiers University of Poitiers, School of Medicine

olivier.mimoz@chu-poitiers.fr

Nicolas MARJANOVIC, MD

Emergency Department and Prehospital Care, University Hospital of Poitiers INSERM CIC1402 U5 ALIVE

nicolasmarjanovic@ free.fr

\section{Corresponding author:}

Nicolas MARJANOVIC, M.D

Emergency Department and Pre-Hospital Care, University Hospital of Poitiers -2, rue de la milétrie

86000 Poitiers - nicolasmarjanovic@free.fr

\section{Authors' contributions}

NM and MG acquired data and wrote the manuscript. ELH provided expertise. JG, MM, ELH and $\mathrm{OM}$ read and were involved in critical appraisal and revision of the manuscript. All authors approved the final manuscript prior to submission.

\section{Sources of financial support}

None 
Arrivé le 8 octobre 2018

Accepté pour publication le 18 décembre 2018 


\section{RESUME}

\section{CONTEXTE}

L'insuffisance cardiaque aiguë (ICA) est une des principales causes de détresse respiratoire aigüe (DRA) chez les patients consultant aux urgences. La ventilation non-invasive (VNI) est un traitement recommandé pour les patients présentant une DRA secondaire à une ICA. Cependant, son intérêt dans la prise en charge des patients très âgés a été peu évalué. L'objectif principal de cette étude a été d'estimer le taux de prescription de VNI pour les patients très âgés avec ICA. Les objectifs secondaires ont été d'identifier les déterminants de la prescription d'une VNI et d'estimer l'association entre la VNI et le pronostic à 8 jours des patients très âgés.

\section{METHODES}

Etude observationnelle rétrospective conduite aux urgences du CHU de Poitiers, évaluant les patients de plus de 75 ans avec ICA avec indication d'une VNI.

\section{RESULTATS}

Deux cent treize patients ont été inclus et une VNI a été prescrites par BiPAP et pour 17.4\%. Les patients ayant reçu une VNI était plus jeune (médiane [interquartile], 85 [91-90] versus 87 [84-92] ans ; p = 0,045) et avait des valeurs de pH plus faible. (7,29 [7,21-7,37] versus 7,41 [7,34-7,41]; p < 0,001). La prescription d'une VNI était associée à l'âge, la $\mathrm{SpO}$, le pH et la pCO2. Elle n'a pas été associé avec une amélioration de la mortalité (OR 0.50 [0,17-1,45]; $\mathrm{p}=0,20)$.

\section{CONCLUSIONS}

Dans notre service d'urgence, la VNI pour ICA a été peu prescrite aux patients âgés et ne semble pas être associé à une amélioration du pronostic, indépendamment des comorbidités et de l'autonomie.

\section{Mots clés}

Personne âgée; insuffisance cardiaque; ventilation non-invasive; service d'urgences

\section{ABSTRACT}

\section{BACKGROUND}

Acute Heart Failure (AHF) is a main cause of acute respiratory failure for patients admitted to Emergency Departments (ED). Non-invasive ventilation (NIV) is recommended as a first-line therapy for acute respiratory failure in patients with AHF, but its role in the ED for very old patients is poorly defined. The primary goal of this study was to estimate NIV prescription for older patients with AHF. Secondary goals 
were to identify determinants of NIV prescription, and to measure the association between NIV and day- 8 outcomes in elderly patients.

\section{METHODS}

Retrospective observational study at the ED of the University Hospital of Poitiers, France, assessing patients over 75 years old with AHF who had indication for NIV.

\section{RESULTS}

A total of 213 patients were included and NIV was only performed as BiPAP and in 17.4\%. Patients who received NIV were younger (median [interquartile range], 85 [81-90] versus 87 [84-92] years; $p=0.045$ ) and had lower $\mathrm{pH}$ values (7.29 [7.21-7.37] versus 7.41 [7.34-7.45]; $\mathrm{p}<0.001)$ than others. NIV prescription was independently associated with Age, $\mathrm{SpO} 2, \mathrm{pH}$ and $\mathrm{pCO}$. NIV was not associated with a better mortality rate (OR $0.50[0.17-1.45] ; \mathrm{p}=0.20)$.

\section{CONCLUSIONS}

In our ED, NIV for AHF is uncommonly performed in the elderly and seems not associated with better outcome in this population regardless of comorbidities and autonomy.

\section{KEYWORDS}

Ederly ; heart failure; non-invasive ventilation; emergency department 
Acute Heart Failure (AHF) is a main cause of acute respiratory failure for patients admitted to Emergency Departments (ED)[1-2], and is associated with high morbidity and mortality[2,3]. Because of increased life expectancy associated with a higher incidence of chronic organ disorder, its incidence has risen progressively with time[4].

Non-invasive ventilation (NIV) is recommended as a treatment in the non-elderly population[5]. NIV allows faster normalisation of clinical parameters and decreases the need for endotracheal intubation compared to standard medical treatment. The European Society of Cardiology's guidelines for AHF management have defined the role and modality of NIV [6]. NIV can be used in very old selected patients admitted to the intensive care unit (ICU)[7,8], with a hospital mortality rate similar to that of younger people. On the contrary, the role of NIV in the ED for very old patients with AHF is poorly defined. We made the hypothesis that NIV was insufficiently performed for the elderly admitted in ED for AHF.

The primary goal of this retrospective cohort study was to estimate the NIV prescription for patients over 75 years old admitted to our ED for AHF. The secondary goals were to identify the determinants of NIV prescription in this population, and to measure the association between NIV and day-8 outcome.

\section{METHODS}

\section{Study design}

We conducted a retrospective observational study at the ED of the University Hospital of Poitiers, France.

Setting

Case-report forms of all patients over 75 years old admitted to ED for dyspnoea associated with AHF between January 2011 and January 2016 were reviewed for eligibility. Data were collected using Resurgences Software (Berger-Levrault, Boulogne-Billancourt, France).

\section{Participants}

All patients over 75 years old and admitted to our Emergency Department for AHF during the analysed period were preselected for the study. The initial diagnosis of AHF was determined by ED physicians during the consultation and used for selection of patients. The diagnosis was confirmed by two independent ED physicians according to symptoms described in the ESC guidelines [6]. In case of discordance, the final diagnosis at the end of hospitalisation was maintained. We included only patients requiring NIV according to the following criteria: (1) acute respiratory failure, with respiratory rate over 25 breaths/min and $\mathrm{SpO} 2<90 \%$ in room air, or < 95\% despite adapted oxygen therapy. (2) Respiratory acidosis was defined by arterial blood $\mathrm{pH}<7.35$ and $\mathrm{PaCO} 2>45 \mathrm{mmHg}$ or $6 \mathrm{kPa}$ [6]. All patients who underwent immediate invasive ventilation and those who presented any contraindication to NIV were excluded. Patients with missing data were likewise excluded. 
NIV was only provided with Bilevel Positive Airway Pressure mode (BiPAP), using an Elisée 250 turbineventilator (Resmed, San Diego, CA, USA), with an inspiratory flow triggering.

NIV was prescribed by physicians with sufficient knowledge due to theorical and practical learning. NIV monitoring was ensure by physicians and by nurses.

\section{Variables}

Primary outcome was the proportion of patients with a NIV prescription.

Secondary outcomes were the association between NIV prescription and patients' outcome and all identified variables associated with NIV prescription. We defined groups as BiPAP+ and BiPAP- if NIV was prescribed or not, respectively. Patients' outcome were hospital length-of-stay and mortality status at Day-2 and Day-8 and in-hospital-mortality. Other data reported were comorbidities according to the Charlson Adjusted Index[9], initial clinical and biological patterns, and autonomy status.

Initial clinical and biological patterns were checked during the two first hours of care, before noninvasive ventilation when performed. Autonomy status was defined according to the AGGIR scale [10] and determined before or during the hospitalization. Patients were considered as autonomous if AGGIR scale was over 4 and with poor autonomy if it was equal to or under than 4.

\section{Statistical analysis}

Data analyses were performed using SPSS 23.0 (IBM Corporation, Armonk, NY, USA). Descriptive data are reported as median and interquartile range or number and proportion, or adjusted odds ratios and 95\% confidence intervals, as appropriate. Univariate analysis was conducted using Mann-Whitney U-test, the log-rank or chi-squared tests, as appropriate. A multivariate Cox regression model was used to analyse Day-8 mortality associated factors. Multivariate models were developed to adjust for relevant variables and from the univariate association $(\mathrm{p}<0.20)$. Statistical significance was defined as $\mathrm{p}<0.05$ for two-tailed tests.

The protocol was approved by the ethic committee of the Société de Réanimation de Langue Française.

\section{RESULTS}

We screened 2,039 patients over 75 years old with primary diagnosis of AHF. We excluded 1801 patients who did not have an indication for NIV and 25 patients who presented exclusion criteria. Overall, we included 213 AHF patients with an indication for NIV according to the 2016 ESC Guidelines [6] (Figure 1). Their characteristics are summarized in Table 1. NIV was performed in 37 (17.4\%) out of the 213 patients who had an indication, using an Elisée 250 (Resmed, San Diego, CA, USA) and was provided in bilevel mode with the following settings:

PEEP $=3$ to $6 \mathrm{~cm} \mathrm{H}_{2} \mathrm{O}$; Pressure Support $=8$ to $12 \mathrm{~cm} \mathrm{H}_{2} \mathrm{O}$; Inspiratory Trigger $=2 \mathrm{~L} / \mathrm{min}$; and $\mathrm{F}_{\mathrm{i}} \mathrm{O} 2$ according to $\mathrm{SpO} 2$ with an objective over $95 \%$. Nitrate derivative were more provided for NIV-patients than other $(\mathrm{p}=0.003)$. Diuretics, antibiotics and beta2-agonist prescription did not differ between groups. 
$\mathrm{BiPAP}+$ patients were significantly younger and had lower $\mathrm{SpO} 2$ and $\mathrm{pH}$ values than $\mathrm{BiPAP}-$ patients (Table 1).

Hospital length-of-stay did not differ between BiPAP+ and BiPAP- $(\mathrm{p}=0.83)$ (Table 1). Mortality rates differed between BiPAP+ and BiPAP- patients from 8 days ( $\mathrm{p}=0.013$ ). Day- 8 mortality was independently associated with age, initial systolic blood pressure and pCO2. However, NIV prescription was not significantly associated with the mortality rate in the univariate (Table 2) and multivariate model (OR 0.50 [0.17-1.45]; $\mathrm{p}=0.20$; Table 3).

\section{DISCUSSION}

In our study, NIV was seldom prescribed when indicated and was not associated with better outcome in elderly patients admitted to our ED for acute respiratory failure (ARF) related to AHF.

\section{NIV indication in the elderly}

In our retrospective cohort analysis, NIV was administered to $17 \%$ of patients with potential indications, and to $2 \%$ of the overall population over 75 years old with AHF.

This low prescription rate could have many explanations. First, ED could be an unfavourable environment in which to begin NIV, because of a lack of training or adherence to NIV, and because this procedure is time-consuming [13]. Secondly, NIV requires the complete compliance and cooperation of the patient to be beneficial[14,15] An altered mental status, commonly associated with age is a brake on its prescription because it may be associated with the failure of NIV[13]. Another reason resides in therapeutic limitations or do-not-resuscitate orders for several patients determined during a previous hospital stay. That much said, selected elderly patients admitted to the ICU have a similar mortality rate compared to younger patients when NIV is applied according to validated indications[6]. Indeed, NIV should constitute a first-line treatment in patients for whom invasive ventilation is questionable[16], but non-admission to the ICU forbids its pursuit and could make its initiation difficult. To explain the low rate of prescription, we must also consider the intensity of the treatment habitually administered to very old patients. The literature has amply demonstrated that hospital resources are allocated preferentially to younger patients[17]. Also, as outlined above, NIV is more frequently used in a younger population[13]. Finally, we could not exclude that physicians did not consider NIV due to the few studies assessing its impact in a very old ED patient population, especially in terms of mortality rate.

Compared to the literature, our prescription rate was lower than those for three studies assessing the therapeutic management of AHF. These previous studies found NIV prescription rate ranging from $4 \%$ to $12.4 \%$ in a general population[2,11,12]. However, none of them specified how many patients had an indication of NIV or showed clinical and biological patterns associated with this prescription. Moreover, none of them put forward specific assessment of the very old patient population.

According to the 2016 ESC guidelines, NIV is indicated for patients with AHF associated with acute respiratory failure or respiratory acidosis[6]. Studies had shown that elderly patients hospitalised for acute 
respiratory failure related to AHF can be treated and should benefit from NIV[7,8]. As suggested by our univariate analysis and a higher day- 8 mortality in NIV+, only the youngest or most severely ill patients received NIV during their ED stay. Others were not being treated with NIV, even though they probably needed it. NIV allow for faster improvement of clinical and biological patterns[18], even if it is not associated with any improvement of the in-hospital mortality rate in the literature [19].

\section{Association between NIV and mortality}

Due to our inclusion criteria, our day-8 and in-hospital mortality rate were higher than data of science [2]. Then, while surviving patients were more frequently treated by NIV, the multivariate model suggest that NIV use was not associated with a reduction of the mortality rate.

This absence of impact in term of mortality is concordant with the literature and could have many explanations. First, in our study, NIV was exclusively administered in BiPAP, i.e. pressure-controlled continuous spontaneous ventilation mode (PC-CSV), and never using continuous positive airway pressure mode (C-PAP). Despite clinical effect in AHF [18], BiPAP is not associated with a significant reduction in in-hospital mortality $[18,19]$. Then, NIV was often prescribed when patients had a major risk of NIV failure. For example, a respiratory rate of over 35 breaths per minute is associated with a higher risk of NIV failure and a higher mortality rate[15]. In our work, $25 \%$ of patients had a severe tachypnea over 35 breaths per minute. Another explanation could be the high proportion of patients with few autonomy or various comorbidities. However, the multivariate model suggested that a lack of autonomy or presence of comorbidities were not associated with mortality, regardless of the initial clinical severity. Data in the literature are contradictory. In a retrospective study, Cosentini et al. highlighted advanced age as a predictor of in-hospital mortality and suggested that the high number of co-morbidities affecting elderly individuals was associated with a high risk of mortality[20]. In another work, the authors found that NIV was a useful therapy for AHF in elderly patients with multiple co-morbidities and a limited performance status [21]. However, this study was slightly different from the present one. Indeed, their patients were younger than ours and the authors assessed NIV efficiency exclusively in acidotic patients, $40 \%$ of whom had a diagnosis of COPD [21]. All in all, only one multicentre prospective randomised trial in ED has assessed NIV efficiency in a population equivalent to ours [7]. In this trial, besides the faster improvement of clinical and biological parameters and a 2-day mortality rate reduction, no sustained benefit was noted during the overall hospital stay [7].

\section{Limits}

Our study suffers from several limitations. First, it was a retrospective analysis of patients who had been admitted one ED and some results were questionable. The choice of the AGGIR scale to estimate the autonomy was perhaps of limited relevance and could also be called into question. However, it is commonly used in French hospitals to estimate the autonomy status of elderly patients. Our first choice was the OMS scale, but it was not to be found in a majority of patients' files. Because physicians' knowledge of NIV management differs from one hospital to another, our results cannot be extrapolated to other hospitals or 
countries. In addition, we could not assess the efficiency of NIV in terms of clinical parameters. It would be interesting to analyse clinical and biological normalisation compared to the mortality rate. Finally, despite an exhaustive analysis of a large number of patients, few was included in the study, and it could be difficult to conclude about NIV's impact in the mortality rate. This low number of inclusions was related, first, to a straight defined population over 75 years old, regularly excluded from many studies and while they are an increasing part of patients attending to the ED, and secondly, to a selection bias. In French medical service, patients with acute respiratory failure are commonly managed by a prehospital emergency medical service (PEMS) and could be directly admitted in ICU. Even if older patients do not beneficiate as much PEMS and ICU as youngers, severest patients could have not been included in the study.

\section{CONCLUSION}

In our ED, NIV for AHF is seldom performed in the elderly having been admitted and was more frequently prescribed for those who were more seriously ill. However, NIV use was not associated with better outcome in this population regardless of their comorbidities and autonomy status. 


\section{REFERENCES}

1. Fonarow GC. Epidemiology and risk stratification in acute heart failure. Am Heart J 2008; 155:2007. https://doi: 10.1016/j.ahj.2006.10.043.

2. Logeart D, Isnard R, Resche-Rigon M, Seronde MF, de Groote P, Jondeau G, et al. Current aspects of the spectrum of acute heart failure syndromes in real-life setting: the OFICA study. Eur J Heart Fail 2013;15:465-76.

3. Schmickl CN, Biehl M, Wilson GA, Gajic O. Comparison of hospital mortality and long-term survival in patients with acute lung injury/ARDS vs cardiogenic pulmonary edema. Chest 2015; 147:618625. https://doi.org/10.1378/chest.14-1371

4. McCullough PA, Philbin EF, Spertus JA, Kaatz S, Sandberg KR, Weaver WD et al. Confirmation of a heart failure epidemic: findings from the Resource Utilization Among Congestive Heart Failure (REACH) study. J Am Coll Cardiol 2002; 39:60-69. https://doi.org/10.1016/S0735-1097(01)01700-4

5. Bersten AD, Holt AW, Vedig AE, Skowronski GA, Baggoley CJ. Treatment of severe cardiogenic pulmonary edema with continuous positive airway pressure delivered by face mask. NEJM 1991; 325:18251830. https://doi.org/10.1056/NEJM199112263252601

6. Ponikowski P, Voors AA, Anker SD, Bueno H, Cleland JGF, Coats AJS et al. 2016 ESC Guidelines for the diagnosis and treatment of acute and chronic heart failure. Eur Heart J 2016; 37:2129. https://doi.org/10.1016/j.rec.2016.11.005

7. L'Her E, Duquesne F, Girou E, de Rosiere XD, Le Conte P, Renault S, et al. Noninvasive continuous positive airway pressure in elderly cardiogenic pulmonary edema patients. Intensive Care Med 2004; 30:882-888. https://doi.org/10.1007/s00134-004-2183-y

8. Vargas N, Vargas M, Galluccio V, Carifi S, Villani C, Trasente V, et al. Non-invasive ventilation for very old patients with limitations to respiratory care in half-open geriatric ward: experience on a consecutive cohort of patients. Aging Clin Exp Res 2014; 26:615-623. https://doi.org/10.1007/s40520-014-0223-1

9. Charlson ME, Pompei P, Ales KL, MacKenzie CR. A new method of classifying prognostic comorbidity in longitudinal studies: development and validation. J Chronic Dis 1987; 40:373-383. https://doi.org/10.1016/0021-9681(87)90171-8

10. Aguilova L, Sauzéon H, Balland E, Consel C, N'Kaoua B. [AGGIR scale. A contribution to specifying the needs of disabled elders]. Revue Neurologique 2014;170. https://doi.org/10.1016/j.neurol.2014.01.039

11. Claret P-G, Stiell IG, Yan JW, Clement CM, Rowe BH, Calder LA, et al. Characteristics and outcomes for acute heart failure in elderly patients presenting to the ED. Am J Emerg Med 2016; 34:21592166. https://doi.org/10.1016/j.ajem.2016.08.015

12. Chouihed T, Manzo-Silberman S, Peschanski N, Charpentier S, Elbaz M, Savary D, et al. Management of suspected acute heart failure dyspnea in the emergency department: results from the French prospective multicenter DeFSSICA survey. Scand J Trauma Resusc Emerg Med 2016;24:112. 
13. Chevrolet JC, Jolliet P, Abajo B, Toussi A, Louis M. Nasal positive pressure ventilation in patients with acute respiratory failure. Difficult and time-consuming procedure for nurses. Chest 1991; 100:775-782. 14. Masip J, Roque M, Sanchez B, Fernandez R, Subirana M, Exposito JA. Noninvasive ventilation in acute cardiogenic pulmonary edema: systematic review and meta-analysis. JAMA 2005; 294:3124-3130. https://doi.org/10.1001/jama.294.24.3124

15. Pacilli AM, Valentini I, Carbonara P, Marchetti A, Nava S. Determinants of noninvasive ventilation outcomes during an episode of acute hypercapnic respiratory failure in chronic obstructive pulmonary disease: the effects of comorbidities and causes of respiratory failure. BioMed Res Int 2014; 2014:976783. https://doi.org/10.1155/2014/976783

16. Benhamou D, Girault C, Faure C, Portier F, Muir JF. Nasal mask ventilation in acute respiratory failure. Experience in elderly patients. Chest 1992; 102:912-917. https://doi.org/10.1378/chest.102.3.912

17. Hamel MB, Phillips RS, Teno JM, Lynn J, Galanos AN, Davis RB, et al. Seriously ill hospitalized adults: do we spend less on older patients? Support Investigators. Study to Understand Prognoses and Preference for Outcomes and Risks of Treatments. J Am Geriatr Soc 1996; 44:1043-1048.

18. Gray A, Goodacre S, Newby DE, Masson M, Sampson F, Nicholl J et al. Noninvasive ventilation in acute cardiogenic pulmonary edema. N Engl J Med 2008; 359:142-51. https:// doi.org/10.1056/NEJMoa0707992

19. Weng CL, Zhao YT, Liu QH, Fu CJ, Sun F, Ma YL, et al. Meta-analysis: Noninvasive ventilation in acute cardiogenic edema. Ann Intern Med 2010; 152:590-600 https://doi.org/10.7326/0003-4819-152-9201005040-00009

20. Cosentini R, Aliberti S, Bignamini A, Piffer F, Brambilla AM. Mortality in acute cardiogenic pulmonary edema treated with continuous positive airway pressure. Intensive Care Med 2009; 35:299-305. https://doi.org/10.1007/s00134-008-1281-7

21. Calvo S, Padilla L. Non Invasive Mechanical Ventilation in Elders with Acute Heart Failure. Austin J Clin Cardiolog 2015; 2:1040.

\section{Acknowledgments}

The authors wish to thank Jeffrey Arsham, an American medical translator, for reviewing and editing our original English-language manuscript.

\section{LEGENDS FOR TABLE/FIGURE}

Figure 1 - Flow-chart

\section{CONFLICT OF INTEREST}

none 
2039 patients

over 75 years old

AND

acute heart failure

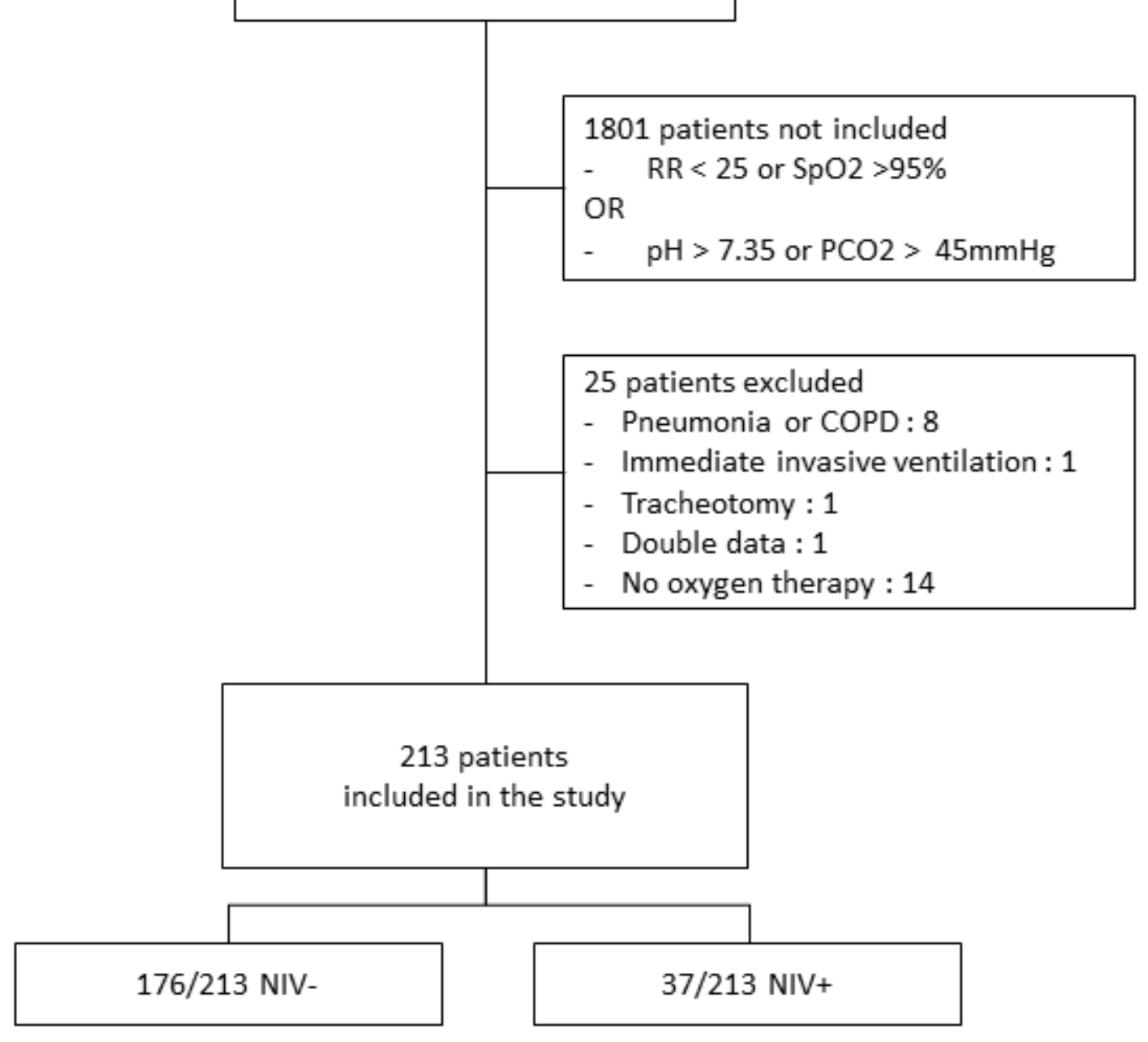


Table 1 -Characteristics of patients $(n=213)$ and Univariate analysis of all patients' characteristics according to prescription of non-invasive ventilation.

\begin{tabular}{|c|c|c|c|c|}
\hline & $\begin{array}{l}\text { Overall } \\
(n=213)\end{array}$ & $\begin{array}{l}\text { BiPAP- } \\
(n=176)\end{array}$ & $\begin{array}{c}\text { BiPAP+ } \\
(n=37)\end{array}$ & $P$ \\
\hline Age (years) & $87[83-91]$ & 87 [84-92] & $85[81-90]$ & 0.045 \\
\hline n(\%) male & $84(39.4)$ & $68(39.2)$ & $15(40.5)$ & 0.88 \\
\hline \multicolumn{5}{|l|}{ Autonomy assessment n $(\%) \dagger$} \\
\hline Autonomous & $61(29)$ & $53(30)$ & $8(22)$ & 0.078 \\
\hline Poor autonomy & $110(52)$ & $86(49)$ & $24(65)$ & \\
\hline \multicolumn{5}{|l|}{ Comorbidities n $(\%) \psi$} \\
\hline $0-1$ & $74(34.7)$ & $53(30)$ & $7(19)$ & 0.17 \\
\hline$\geq 2$ & $139(65.3)$ & $129(70)$ & $30(81)$ & \\
\hline \multicolumn{5}{|l|}{ Clinical patterns } \\
\hline Temperature $\left({ }^{\circ} \mathrm{C}\right)$ & $37[36.4-37.6]$ & $37[36.5-37.6]$ & $36.8[35.9-37.5]$ & 0.09 \\
\hline $\mathrm{SpO} 2(\%)$ & 93 [91-94] & $93[91-94]$ & $88[85-93]$ & 0.001 \\
\hline Respiratory rate (cycles/min) & $31[28-37]$ & $31[28-36]$ & $32[28-39]$ & 0.52 \\
\hline Heart rate $(\mathrm{bpm})$ & $85[67-104]$ & $82[67-102]$ & $92[62-109]$ & 0.19 \\
\hline Systolic Blood Pressure (mmHg) & $137[118-156]$ & $136[118-156]$ & $144[121-158]$ & 0.48 \\
\hline \multicolumn{5}{|l|}{ Biological patterns } \\
\hline $\mathrm{pH}$ & $7.38[7.32-7.44]$ & $7.41[7.34-7.45]$ & $7.29[7.21-7.37]$ & $<0.001$ \\
\hline $\mathrm{pCO} 2(\mathrm{mmHg})$ & $44[35-56]$ & $41[35-51]$ & $60[48-80]$ & $<0.001$ \\
\hline pO2 (mmHg) & 68 [59-82] & $68[60-81]$ & $70[57-91]$ & 0.037 \\
\hline HCO3- (mEq/L) & $26[22-30]$ & 25 [21-29] & $26[23-35]$ & 0.03 \\
\hline \multicolumn{5}{|l|}{ Other therapeutics } \\
\hline Diuretic & $187(88)$ & $152(86)$ & $35(94)$ & 0.16 \\
\hline Nitrate derivative & $104(49)$ & $47(27)$ & $20(54)$ & 0.002 \\
\hline Beta-2 agonist & $34(16)$ & $28(16)$ & $6(16)$ & 0.96 \\
\hline Antibiotic & $57(27)$ & $49(28)$ & $8(22)$ & 0.44 \\
\hline Hospital length-of stay (days) & $14[6-17]$ & $12[7-17]$ & $11[3-17]$ & 0.83 \\
\hline \multicolumn{5}{|l|}{ Mortality rate $\mathrm{n}(\%)$} \\
\hline 2-day & $10(4.7)$ & $6(3.4)$ & $4(10.8)$ & 0.053 \\
\hline 8-day & $30(14.1)$ & $20(11.4)$ & $10(27)$ & 0.008 \\
\hline In-hospital mortality & $57(22.1)$ & $34(19.3)$ & $13(35.1)$ & 0.031 \\
\hline
\end{tabular}

$\dagger$ Autonomy was evaluated among the last medical assessment of the patient’s autonomy, and for 171 patients. $\ddagger$ Co-morbidities were identified according to Charlson comorbidities index. 
Table 2 - Univariate analysis according to the Day-8 survival

\begin{tabular}{|c|c|c|c|}
\hline & $\begin{array}{c}\text { Dead } \\
(n=30)\end{array}$ & $\begin{array}{c}\text { Alive } \\
(n=183)\end{array}$ & $P$ \\
\hline Age (years) & $91[85-95]$ & $87[83-91]$ & $\mathbf{0 . 0 0 7}$ \\
\hline $\mathrm{n}(\%)$ male & $7(23.3)$ & $77(42.1)$ & \\
\hline \multicolumn{4}{|l|}{ Autonomy assessment $\mathrm{n}(\%) *$} \\
\hline Autonomous & 4 & 57 & $\mathbf{0 . 0 3 9}$ \\
\hline Poor autonomy & 20 & 90 & \\
\hline \multicolumn{4}{|l|}{ Comorbidities n $(\%) \dagger$} \\
\hline $0-1$ & $12(40)$ & $62(33.9)$ & 0.51 \\
\hline$\geq 2$ & $18(60)$ & $121(66.1)$ & \\
\hline \multicolumn{4}{|l|}{ Clinical patterns } \\
\hline Temperature $\left({ }^{\circ} \mathrm{C}\right)$ & $37[36.2-38]$ & $37[36.4-37.6]$ & 0.85 \\
\hline $\mathrm{SpO} 2(\%)$ & 90 [87-93] & $93[91-94]$ & 0.001 \\
\hline Respiratory rate (cycles/min) & $32[28-40]$ & $31[28-36]$ & 0.25 \\
\hline Heart rate (bpm) & $95[69-110]$ & 82 [66-103] & 0.26 \\
\hline Systolic Blood Pressure (mmHg) & $126[109-143]$ & 140 [120-159] & 0.004 \\
\hline \multicolumn{4}{|l|}{ Biological patterns } \\
\hline $\mathrm{pH}$ & $7.31[7.19-7.41]$ & $7.39[7.33-7.45]$ & 0.007 \\
\hline $\mathrm{pCO} 2(\mathrm{mmHg})$ & 54 [40-79] & $43[35-53]$ & $\mathbf{0 . 0 1 2}$ \\
\hline $\mathrm{pO} 2(\mathrm{mmHg})$ & 68 [58-90] & $68[60-82]$ & 0.89 \\
\hline HCO3- (mEq/L) & $26[22-34]$ & 25 [22-29] & 0.36 \\
\hline \multicolumn{4}{|l|}{ Other therapeutics } \\
\hline Diuretics & $25(83)$ & $162(89)$ & 0.61 \\
\hline Nitrate derivative & $8(27)$ & $59(32)$ & $\mathbf{0 . 5 3}$ \\
\hline Beta2-agonist & $7(23)$ & 27 (15) & 0.82 \\
\hline Antibiotics & $8(27)$ & $45(25)$ & 0.36 \\
\hline NIV providing & $20(66.7)$ & $156(85.2)$ & 0.012 \\
\hline
\end{tabular}

*Autonomy was evaluated among the last medical assessment of the patient's autonomy, and for 171 patients. $†$ Co-morbidities were identified according to Charlson comorbidities index. 
Table 3 - Cox model regression of the Day-8 mortality status

\begin{tabular}{|l|c|c|c|}
\hline & OR & CI95\% & p \\
\hline Age & 1.11 & $1.02-1.22$ & 0.021 \\
\hline Autonomous & 0.30 & $0.07-1.35$ & 0.12 \\
\hline Systolic Blood Pressure & 0.98 & $0.96-0.998$ & 0.028 \\
\hline pCO2 & 1.03 & $1.01-1.06$ & 0.003 \\
\hline NIV providing & 0.50 & $0.17-1.45$ & 0.20 \\
\hline
\end{tabular}

Day-8 mortality status was significantly associated with Age, Systolic Blood Pressure and pCO2. 